\title{
HUBUNGAN KETERPAPARAN PORNOGRAFI DI INTERNET DENGAN SIKAP BERPACARAN REMAJA PADA KELAS XI DI SMK NU 02 ROWOSARI KABUPATEN KENDAL
}

\author{
Budi Astyandini ${ }^{1}$, Khobibah $^{2}$, Ma'rifatul Laely $^{3}$ \\ 1,2,3 UPP Kampus Kendal Poltekkes Kemenkes Semarang
}

\begin{abstract}
Teenagers often experience problems related to sexuality or reproductive health. $A$ lot of information through the means of the print, electronic broadcast is vulgar and not educational, but more likely to influence and encourage irresponsible sexual behavior. The design of this study uses analytic surveys with cross sectional approaches. The population is class XI students, amounting to 225 students. The research sample of 70 respondents. The sampling technique uses simple random sampling. The type of analysis used is univariate, bivariate and Chi Square test. The research instrument used a questionnaire that was previously tested for validity and reliability. The results of this study showed that most students were exposed to pornography on the internet with a total of 48 students (68.6\%). And positive teen dating attitudes 58 students (82.9\%). From the results of this study, the $p$ value was $0.013<0.05$. This study concluded that there was a relationship between pornography exposure on the internet and the attitude of adolescent dating in class XI at SMK NU 02 Rowosari. It is expected that adolescents should increase knowledge about reproductive health and enhance positive activities. The teachers put more emphasis on moral education so that students avoid the negative effects of exposure to electronic or internet facilities that deviate and avoid the negative effects of bad dating behavior.
\end{abstract}

Keywords: Exposure, Pornography, Internet, Attitude, Dating 


\section{PENDAHULUAN}

Masa remaja merupakan masa khusus dan penting, remaja memerlukan adaptasi terhadap perubahan fisik maupun piskologisnya (Saroha, 2009; h. 302). Remaja dapat dikategorikan berdasarkan perubahan fisik yang terjadi menurut James Traore (2001: 12) yaitu masa remaja awal (10-14), masa remaja pertengahan (15-19 tahun), dan dewasa muda (20-24 tahun).

Berdasarkan hasil survey indikator RPJMN tahun 2012 diantara remaja yang berpacaran sebanyak $26 \%$ melakukan ciuman bibir dan $18 \%$ meraba pasangannya serta $4 \%$ remaja laki-laki dan $1 \%$ remaja perempuan sudah melakukan seksual sebelum menikah. (mardiya, 2013). Informasi melalui sarana masa cetak, elektronik yang ditayangkan secara vulgar dan bersifat tidak mendidik, cenderung mempengaruhi dan mendorong perilaku seksual yang tidak bertanggung jawab. Keterpaparan remaja terhadap pornografi dalam bentuk bacaan berupa buku porno, melalui film porno semakin meningkat. Kosultasi seks yang diberikan melalui sarana cetak dan elektronik yang disebut sebagai pendidikan seks, penanyangan film tertentu di televisi dapat menyebabkan salah persepsi / pemahaman yang kurang tepat terhadap kesehatan reproduksi. Di sisi lain bahan bacaan tentang kesehatan reproduksi dan penerangan melalui sarana yang bersifat audio visual sangat terbatas dan kalaupun ada bentuknya kurang menarik bagi remaja (Saroha, 2009; h. 312). Pemahaman yang kurang tepat terhadap kesehatan reproduksi. Di SMK NU 02 Rowosari Kabupaten Kendal terdapat kasus berhubungan dengan murid yang mengundurkan diri dengan alasan menikah serta beberapa murid yang menyatakan pernah mengakses situs pornografi.

Kesehatan Reproduksi Remaja (KRR) yaitu kondisi sehat dari sistem, fungsi, dan proses alat reproduksi yang dimiliki oleh remaja, yaitu laki-laki dan wanita usia 1024 tahun (BKKBN-UNICEF, 2004) (Kumalasari, 2013; h. 12).

Asmani (2012; h. 38) remaja yaitu fase peralihan antara masa kanak-kanak dan masa tumbuh dewasa, baik secara fisik, akal, kejiwaan, sosial, dan emosional. Pandangan ini diperkuat oleh teori Piaget, "Secara psikologis, masa remaja yaitu usia saat individu berintegrasi dengan masyarakat dewasa, usia saat anak tidak merasa di bawah tingkat orang-orang yang lebih tua, melainkan berada dalam tingkatan yang sama, sekurang-kurangnya dalam masalah hak.

Remaja laki-laki sudah bisa melakukan fungsi reproduksi bila telah mengalami mimpi basah. Mimpi basah biasanya terjadi pada remaja laki-laki usia antara 10-15 tahun. Mimpi basah sebetulnya merupakan salah satu cara tubuh laki-laki ejakulasi. Ejakulasi terjadi karena sperma yang terus-menerus diproduksi perlu 
dikeluarkan. Ini yaitu pengalaman yang normal bagi semua remaja laki-laki.

Dampak Meluasnya peredaran pornografi di masyarakat tentu saja meresahkan, karena sudah banyak penelitian yang mengatakan bahwa dampak peredaran pornografi membahayakan bagi siapapun yang melihatnya, terutama anak-anak dan remaja yang sedang dalam masa perkembangan. Murahnya biaya agar dapat mengonsumsi bahkan memiliki fotofoto atau video porno. Remaja kini bisa mengunduhnya dari berbagai situs porno dan menyimpannya dalam flashdisk. Sikap keterbukaan masyarakat, termasuk orang tua yang terlalu modern sehingga membiarkan anak-anak mereka terlalu bebas dalam menjalani masa muda. Akibatnya, kontrol sosial terhadap akses pornografi menjadi berkurang. (Asmani,. 2012. h. 136-138) Sikap merupakan reaksi atau respons yang masih tertutup dari seseorang terhadap suatu stimulus atau objek (Notoatmodjo, 2012; h. 140)

\section{METODOLOGI PENELITIAN}

Populasi siswa kelas XI SMK NU 02 Rowosari Kabupaten Kendal yang berjumlah 225 siswa. teknik sampel secara propotional random sampling. Kuesioner yang digunakan agar mengetahui keterpaparan pornografi di internet dan sikap berpacaran remaja uji statistik bivariat yang digunakan adalah uji Chi Square.
HASIL PENELITIAN DAN BAHASAN

Tabel 1. Distribusi frekuensi keterpaparan pornografi di internet pada remaja SMK NU 02 Rowosari

\begin{tabular}{lcc}
\hline $\begin{array}{l}\text { Keterpaparan } \\
\begin{array}{l}\text { Pornografi } \\
\text { Internet }\end{array}\end{array}$ & $\begin{array}{c}\text { Frekuensi } \\
\text { (f) }\end{array}$ & $\begin{array}{c}\text { Prosenta } \\
\text { se(100\%) }\end{array}$ \\
\hline Terpapar & 48 & 68,6 \\
Tidak & 22 & 31,4 \\
Terpapar & & \\
\hline Total & 70 & 100,0 \\
\hline
\end{tabular}

Tabel 2. Distribusi frekuensi sikap berpacaran remaja di SMK NU 02 Rowosari

\begin{tabular}{lcc}
\hline $\begin{array}{l}\text { Sikap } \\
\text { Berpacaran }\end{array}$ & $\begin{array}{l}\text { Frekuensi } \\
\text { (f) }\end{array}$ & $\begin{array}{l}\text { Prosentase } \\
(100 \%)\end{array}$ \\
\hline Positif & 58 & 82,9 \\
Negatif & 12 & 17,1 \\
\hline Total & 70 & 100,0 \\
\hline
\end{tabular}

Berpacaran yaitu serangkaian aktivitas bersama yang mewarnai keintiman (seperti adanya rasa kepemilikan dan keterbukaan diri) serta adanya keterikatan emosi antara pria dan wanita yang belum menikah dengan tujuan agar saling mengenal dan melihat kesesuaian antara satu sama lain sebagai pertimbangan sebelum menikah. Persepsi yang positif terhadap pacaran akan mendorong remaja memutuskan agar melakukan pacaran. Remaja berpersepsi pacaran yaitu sebuah kebutuhan bagi remaja selain itu pacaran yang dapat dijadikan pengalaman sebelum melakukan pernikahan, dengan berpacaran remaja akan mengenal karakteristik dari lawan jenis, terutama orang yang dicintainya. Namun pacaran dianggap sebagai jati diri 
pergaulan dan identitas kedewasaan, meskipun pada kenyataannya banyak aktivitas yang menjurus pada perilaku seks tidak aman. (Hakim, 2014; h.7).

Siswa yang tidak terpapar pornografi mempunyai sikap berpacaran yang positif. mereka mencari informasi mengenai seksualitas tidak harus melalui internet, mereka bisa bertanya kepada teman sebaya atau dengan membaca dan mempelajari tentang seksualitas dalam agamanya karena sekolahan ini berbasis islamiah sehingga mereka mungkin takut melanggar norma agama maupun sosial.

Sikap negatif responden, dikarenakan ketidakmampuan diri dalam mengontrol dirinya agar menonton gambar ataupun video porno sehingga mereka terus menerus ingin menontonnya karena dampak pornografi sama dengan dampak narkoba yaitu adanya sifat adiktif. Orang akan ketagihan bila mengkonsumsi materi Pornografi, sama dengan narkoba pornografi juga menyerang otak.

Hasil dari siswa yang terpapar pornografi di internet yang mempunyai sikap negatif sebanyak 12 responden, hal ini mungkin dikarenakan ketidakmampuan diri dalam mengontrol dirinya agar menonton gambar ataupun video porno sehingga mereka terus menerus ingin menontonnya karena dampak pornografi sama dengan dampak narkoba yaitu adanya sifat adiktif. Orang akan ketagihan bila mengkonsumsi materi pornografi, sama dengan narkoba pornografi juga menyerang otak. Selain itu juga pengaruh dari lingkungan sekitar atau kurangnya kegiatan-kegiatan yang positif di sekolah maupun diluar sekolah menyebabkan remaja mengekspresikan sikap berkaitan dengan munculnya kabutuhan biologis dari hormon seksualitas ke arah yang negatif. Namun tidak semua siswa yang terpapar materi pornografi di internet mempunyai sikap negatif, justru mereka sebagian besar mempunyai sikap yang positif. $\mathrm{Hal}$ ini dikarenakan mereka hanya penasaran ingin melihat gambar atau video pornografi saja tetapi mereka tidak mengkonsumsinya secara terus menerus. Alasan lainnya mereka ada yang tidak mempunyai pasangan atau kekasih sehingga mereka tidak tahu mau mengekspresikan seksualitasnya kepada siapa.

Tabel 3. Distribusi frekuensi hubungan keterpaparan pornografi di internet dengan sikap parcaran remaja di SMK NU 02 Rowosari

\begin{tabular}{|c|c|c|c|c|c|}
\hline \multirow{3}{*}{$\begin{array}{l}\text { Keterpaparan } \\
\text { Pornografi }\end{array}$} & & & \multicolumn{3}{|l|}{ Sikap } \\
\hline & & & & & \\
\hline & & Positif & Negatif & Total & $p$-value \\
\hline \multirow[t]{2}{*}{ Tidak Terpapar } & Jumlah (n) & 22 & 0 & 22 & \\
\hline & Presentase (\%) & $31,4 \%$ & $0 \%$ & $31,4 \%$ & 0.013 \\
\hline \multirow[t]{2}{*}{ Terpapar } & Jumlah (n) & 36 & 12 & 48 & \\
\hline & Presentase (\%) & $51,4 \%$ & $17,1 \%$ & $68,6 \%$ & \\
\hline \multirow[t]{2}{*}{ Total } & Jumlah (n) & 58 & 12 & 70 & \\
\hline & Presentase (\%) & $82,9 \%$ & $17,1 \%$ & $100 \%$ & \\
\hline
\end{tabular}

Keterpaparan pornografi di internet dipengaruhi oleh sikap remaja serta kurangnya pengawasan guru dan orang tua dalam mengakses internet, orang tua dan guru cenderung tertutup ketika membahas pendidikan seks sehingga 
remaja penasaran kemudian mencari jawaban diluar sekolah ataupun rumah melalui sarana internet. Orang tua juga memberikan fasilitas gadget yang memudahkan mengakses situs pornografi.

Sikap berpacaran remaja selain dipengaruhi paparan sarana pornografi juga dipengaruhi orang lain atau teman sebaya serta faktor emosional pada remaja.

Masalah seks dan seksualitas dipengaruhi oleh beberapa hal yaitu Pengetahuan yang tidak tepat, Kurang bimbingan agar bersikap positif, Penyalahgunaan napza, Penyalahgunaan seksual, Kehamilan pranikah dan akses pornografi.

Pornografi yaitu gambar, sketsa, ilustrasi, foto, tulisan, suara, bunyi, gambar bergerak, animasi, kartun, percakapan, gerak tubuh, atau bentuk pesan lainnya melalui berbagai bentuk sarana komunikasi dan pertunjukan di muka umum, yang memuat kecabulan atau ekspresi seksual yang melanggar norma kesusilaan dalam masyarakat. (Hakim, 2014 h. 52).

Ragam informasi tentang pornografi yang beredar di masyarakat (Subagijo, 2010; h. 36):Sexually violent material, yaitu materi pornografi dengan menyertakan kekerasan. Nonviolent material depicting degradation, dominatiton, subordination, or humiliation. Meskipun jenis ini tidak menggunakan kekerasan dalam materi seks yang disajikannya, di dalamnya terdapat unsur yang melecehkan perempuan, misalnya adegan melakukan seks oral atau "dipakai" oleh beberapa pria, atau melakukan hubungan seks dengan binatang. Dan Nonviolent and nondegrading materials yaitu produk sarana yang memuat adegan hubungan seksual tanpa unsur kekerasan atau pelecehan terhadap perempuan. Misalnya adegan pasangan yang melakukan hubungan seksual tanpa paksaan. Nudity, yaitu materi seksual yang menampilkan model telanjang, misalnya majalah Playboy.Child Pornography yaitu produk sarana yang menampilkan anak atau remaja sebagai modelnya.

Sebagian besar responden di SMK NU 02 Rowosari terpapar pornografi di internet 48 responden (68,6\%). Sebagian besar responden di SMK NU 02 Rowosari sikap berpacarannya positif 58 responden $(82,9 \%)$.Terdapat hubungan antara keterpaparan pornografi di internet dengan sikap berpacaran remaja pada kelas XI di SMK NU 02 Rowosari Kendal dengan $p$ value 0,013 .

\section{KESIMPULAN}

Sebagian besar responden di SMK NU 02 Rowosari terpapar pornografi di internet 48 responden (68,6\%). Sebagian besar responden di SMK NU 02 Rowosari sikap berpacarannya positif 58 responden (82,9\%).Terdapat hubungan antara keterpaparan pornografi di internet dengan sikap berpacaran remaja pada kelas XI di SMK NU 02 Rowosari Kendal dengan $p$ value 0,013 . 


\section{DAFTAR PUSTAKA}

1. Ariani, Ayu. 2014. Aplikasi metodologi Penelitian Kebidanan dan Kesehatan Reproduksi. Yogyakarta: Nuha Medika.

2. Asmani, Jamal Ma'mur. 2012. Kiat Mengatasi Kenakalan Remaja di Sekolah. Yogyakarta: Buku Biru.

3. Azwar, Saifuddin. 2014. Metode Penelitian. Yogyakarta: Pustaka Pelajar.

4. Hakim, Lukman. 2014. Fenomena Pacaran Dunia Remaja. Riau: Zanafa Publishing.

5. Harlock, Elizabeth. Psikologi Perkembangan Edisi kelima. Jakarta: Penerbit Erlangga.

6. Hidayat, A. 2012. Metode Penelitian Kebidanan dan Teknik Analisis Data. Jakarta: Salemba Medika.

7. Imron, Ali. 2012. Pendidikan Kesehatan Reproduksi Remaja. Yogyakarta: Ar-ruzz Sarana.

8. Iwan, Slam. 2010. Boleh Ngaak Sih, Masturbasi? Dan 101 Pertanyaan Tentang Seks Agar Remaja. Yogyakarta: Andi Offsest.

9. Kumalasari, Intan dan Andhyantoro, Iwan. 2013. Kesehatan Reproduksi agar Mahasiswa Kebidanan dan Keperawatan. Jakarta: Salemba Medika.

10. Kusmiran, Eny. 2013. Kesehatan Reproduksi Remaja dan Wanita. Jakarta: Salemba Medika.
11. Manuaba, dkk. 2009. Memahami Kesehatan Reproduksi Wanita Edisi 2. Jakarta: Buku Kedokteran EGC.

12. Mardiya. Hari kependudukan sedunia tahun 2013 saatnya tahu dan peduli terhadap masalah remaja. Kulon Progo: Artikel Kesehatan Reproduksi: 2013.

13. Marmi. 2013. Kesehatan Reproduksi. Yogyakarta: Pustaka Pelajar.

14. Murti Indah. Hubungan antara Frekuensi Paparan Sarana Pornografi melalui Sarana Massa dengan Tingkat Perilaku Seksual. Depok: Jurnal Kesehatan Masyarakat; 2008.

15. Nuryani I dan Pratami F. Hubungan keterpaparan sarana informasi tentang seks dengan perilaku seks remaja awal. Semarang: jurnal kebidanan; 2011.

16. Rohan HH dan Siyoto. 2013 Kesehatan Reproduksi. Yogyakarta: Nuha Sarana.

17. Riwidikdo, Handoko. 2012. Statistik Kesehatan. Yogyakarta: Nuha Medika.

18. Saryono. 2011. Metodologi Penelitian kesehatan. Yogyakarta: Mitra Cendikia.

19. Setiawan dan Saryono. 2011. Metodologi Penelitian Kebidanan DIII, DIV, S1 dan S2. Yogyakarta: Nuha Medika.

20. Sugiyono. 2014. Metode Penelitian Kuantitatif Kualitatif dan $R \& D$. Bandung: Alfabeta. 